\title{
EL RELATO LITERARIO COMO CONFIGURADOR DE UN REFERENTE HISTORICO: TERMINA EL DESFILE.DE REINALDO ARENAS
}

\author{
POR \\ MYRNA SOLOTOREVSKY \\ Universidad Hebrea de Jerusalén
}

Es nuestro propósito analizar la relación propuesta: "historia y ficción", considerando el modo peculiar como un texto literario - es decir, ficticio-; Termina el desfile $e^{1}$, configura un referente histórico: la revolución cubana.

A partir de lo enunciado se desprende nuestra posición: asumimos que el referente no existe fuera del texto y es luego imitado por éste, sino que se constituye en el texto mismo. Barthes ha señalado a este respecto: "dans le roman le plus réaliste, le référente n'a pas de 'réalitée's'.

Situándonos en una perspectiva teórica, es posible postular que un discurso literario que finge reproducir un referente histórico, hará uso de determinados procedimientos destinados a suscitar la ilusión mimética. Un problema que nos interesará será el concerniente al grado de mayor o menor equilibrio en tre dicha ilusión y la presencia de lo escritural, la que supone un debilitamiento 0 anulación de operadores de legibilidad.

El planteamiento que proponemos insta a realizar la distinción entre un discurso histórico y uno literario, a ver cómo el uno y el otro configuran crean-su referente. Como ha afirmado Carrard ${ }^{3}$, la diferencia mayor entre ambos discursos residiría en una cierta relación a lo verdadero y en el contrato de lectura que en ambos casos se desarrolla; en contraste con la literatura, la historia tiende a la verdad referencial en un sentido muy preciso, el de la verificabilidad en los archivos; de acuerdo a ello, y distintamente de lo que sucede en el texto literario, el histórico aspira a resolver todas las ambigüedades. El discurso histórico positivista -que pretende la verdad y la objetividad- aparece, no obstante, como fuente de paradojas: aun la presentación más neutra está orientada, aunque sea -como señala Carrardpor la voluntad de neutralidad, y la ideología estará siempre presente, en un grado mayor o menor de explicitación. Así como la ficción, la "realidad" aparece

\footnotetext{
1 Reinaldo Arenas, Termina el desfile (Barcelona: Seix Barral, 1981).

2 Roland Barthes, $S / Z$. (Paris: Seuil, 1970) 87.

${ }^{3}$ Philippe Carrard, "Recit historique el fonction testimoniale", Poélique 65 (1986): 47 61.
} 
a la luz de estas ideas como una pura construcción. Citando otro texto de Barthes: "en la historia 'objetiva' lo 'real' es siempre sólo un significado no formulado que se refugia tras la apariencia omnipotente del referente ${ }^{n /}$.

La paradoja instituida por el texto literario es de índole distinta: por aceptar su carácter ficticio, el lector se entrega a dicho objeto con una credulidad sin reservas (Martínez Bonati ${ }^{5}$ ); el texto literario no podría sino ofrecer la verdad indiscutible de la ficción y en él la ideología y la subjetividad pueden llegar a manifestarse del modo más desembozado.

Termina el desfile es un texto constituido por nueve relatos; el referente histórico señalado es perceptible en cuatro de ellos: "Comienza el desfile" (CD), "La Vieja Rosa", "Los heridos", "Termina el desfile" (TD), pudiendo dicho referente ser abstraído de la totalidad de la trama de CD y TD - relatos de los cuales nos ocuparemos-, de una parte extensa y culminante de la trama de "La Vieja Rosa" y de un momento incidental pero significativo de la trama de "Los heridos". Los cinco cuentos restantes constituyen, desde la perspectiva que asumimos, especies de islotes ficticios en los que la dimensión histórica se ha desvanecido.

CD y TD -el primer y el último relato del texto, respectivamente-. constituyen los dos polos del proceso histórico que la obra como totalidad diseña: la iniciación de la revolución cubana y su instauración. La elección del segundo título señalado, "Termina el desfile", evidencia desde el paratexto - con toda claridad en la relectura - el sistema apreciativo de la obra, su jdeología antirrevolucionaria: nos sitúa dicho título en un período de acabamiento en el cual la euforia en $\mathrm{CD}$ aparentemente adjudicable al desfile, como gozosa manifestación colectiva, se ha disipado; TD patentizará precisamente la atmósfera profundamente disfórica que entonces prevalece.

Asumiendo los puntos antes teóricamente planteados, veamos primera. mente qué elementos contribuyen en $\mathrm{CD}$ a operar como connotadores de realidad, creando una ilusión referencial:

a) Presencia frecuente de topónimos que conectan con el extratexto, e.g. Holguín, sierra de Gibara, Velasco, etc.

b) Señalización de un antropónimo clave en la dimensión histórica: Batista.

c) Citación de frases que cumplen una función de lemas o consignas en el ámbito de la revolución cubana: "Viva Cuba libre" (p. 8); "Viva Cuba, cojones" (p. 18); “iparedón, paredón!” (p. 19).

d) Abundancia de descripciones eminentemente miméticas, e.g. la siguiente descripción del avance de la revolución: "Están ya en Bayamo'. 'Están ya en Cacocún'. 'Tomaron la Chomba'. 'Entraron anoche en la Loma de la Cruz'

\footnotetext{
${ }^{4}$ Roland Barthes, "El discurso de la historia", en Estructuralismo y lileralura (Buenos Aires: Nueva Visión, 1970) 49.

${ }^{B}$ Félix Martínez Bonati, La estructura de la obra literaria (Santiago: Ediciones de la Universidad de Chile, 1960).
} 
(p. 11), o la descripción siguiente del desfile: "Tenía yo razón: la gente que viene detrás cantaba. Está cantando; alguien trae una guitarra. Al pasar por el río Lirio, las risas, los cantos y el tropel de caballos es tremendo" (p. 10).

No obstante la presencia de los elementos señalados, el relato desdeña otros posibles connotadores de mimesis y hace uso de operadores de escribibilidad, comprometiendo al lector, en menor of mayor grado, en una participación constructiva del texto:

a) CD está configurado por un narrador homodiegético, siempre presente como mediatizador en la plasmación de mundo; el proceso de enunciación adquiere así preeminiencia, atentando contra la pura transparencia del discurso.

b) El héroe del relato - personaje innominado- no opera como factor anulador de la ambigüedad; él mismo es, por el contrario, un personaje indeciso y ambiguo, que no ostenta las cualidades morales o psicológicas valoradas en el mundo configurado ni en el extratexto, sino - como veremos-las antitéticas, valorables en función de la intencionalidad ideológica que impregna al relato.

c) Un factor fundamental que atenta contra la legibilidad es el peculiar sujeto del texto: éste destruye la linealidad y exige un verdadero esfuerzo del lector para distinguir secuencias temporales que el relato intencionalmente confunde. CD se inicia in medias res, cuando ya se ha constituido el desfile:

DETRAS - pero casi junto a mi - viene Rigo, silbando y haciendo rechinar sus botas. $\mathrm{Y}$ después, las hijas de los Pupos (...) Y más atrás vienen los Estradas, y Rafael Rodríguez, y los hijos de Bartolo Angulo (p. 7).

Sin solución de continuidad, salvo la señalada por el cambio de tiempo, de presente a pretérito imperfecto, y por la presencia de tres puntos suspensivos, se pasa a una secuencia anterior, que configura al narrador-personaje llenando latas de agua, viviendo en casa de su tía Olga. Como una concesión, se distinguirá en lo sucesivo, el discurso correspondiente al presente del desfile, mediante el empleo de cursivas. Continuará la alternancia entre presente y momentos del pasado que se remontan, progresivamente, hasta la descripción de la situación que instó al personaje a alzarse ("Por eso y por qué sé yo cuantas cosas más”. [p. 11]) y asumen luego una dirección prospectiva. Los juegos destinados a crear confusión coexisten con las señaladas pautas clarificadoras, e.g., a continuación de una mención de la escopeta de Rigo, correspondiente al presente del desfile, se introduce el siguiente discurso del pasado: "Tira un tiro". me dijiste" (p. 9); el énfasis en la temporalidad, haría creer, en el siguiente caso, en la continuidad del discurso: "Dentro de cinco minutos entraremos en Holguín. Espero a la media noche para entrar en el pueblo" (p. 15); en una recepción puramente fónica del texto, se crea la apariencia de construcciones causales y adversativas: "Pero las manos me siguen sudando como siempre. Porque todo es insoportable" (p. 10); "El me sigue hablando. Pero no hay ni un rebelde en este 
pueblo" (p. 13). Hacia el final del texto, se abandonan las cursivas para la configuración del presente, volviéndose al sistema gráfico del comienzo del relato.

La ideología desmitificadora de la revolución a que aludiéramos, se evidencia a través de las siguientes instancias del relato:

a) El protagonista - cuya ambigüedad hemos destacado-resulta ser un anti-héroe, suscitador de ironía; su alzarse no se conecta a ningún motivo ideológico; su permanencia entre los rebeldes se reduce a un "sin hacer nada" $(p$. 9); el acto de dar muerte a un casquito, que le hubiera permitido cruzar la frontera y transformarse en un personaje dinámico ${ }^{6}$, no es realizado; mientras la revolución se desarrollaba, él ha estado escondido en casa de su tía Olga; él se ha agregado - como otros que no pretendieron alzarse-a último momento al desfile, y los gestos y palabras de reconocimiento que le son dirigidos - por aquellos que conocen la verdad-suscitan una reacción irónica en el lector: "Y ahora llega abuelo, desde la venduta con una bandera roya y negra y un 26 enorme en el centro. 'Caray, muchacho', dice y me entrega la bandera. 'Sal a la calle con ella -me dice mamá-, todos los vecinos te están esperandom (pp. 20 y s.). En un plano simbólico, el cuchillo - posible símbolo fálico-primero tan valorado por el protagonista y finalmente colocado en el borde del inodoro, muestra el fracaso del personaje. El verdadero héroe es Rigo - objeto del deseo del narrador - a quien no corresponde un rol central en la trama.

b) El desfile oculta tras su apariencia carnavalesca, eufórica, una realidad disfórica, a la que es muy sensible el narrador; en ella prevalecen el ruido y el polvo:

La gente, y después los perros que ladran asustados, que se revuelcan en la polvareda; que gritan cuando alguien los patea desconsideradamente. $\mathrm{Y}$ luego el rechinar de las carretas, el tropel de los caballos; el ruido de los camiones (p. 17).

El desfile es, en efecto, "Ta gran polvareda" (p. 14); "polvo" es el último lexema constitutivo del relato.

c) Degradación de símbolos: "Miles y miles de banderas colocadas con urgencia hasta en los más mínimos recovecos. Trapos rojos y trapos negros. Papeles de colores. Papeles, papeles. Trapos" (p. 19); dicha degradación culmina con el acto del protagonista: "y tiro la bandera en el baño" (p. 21).

Acatando la sugerencia de los títulos, TD aparece como la prolongación y culminación de este primer relato: la apariencia eufórica se ha anulado y la disforia y la ideología asumida se manifiestan aquí con la máxima ostensibilidad. Las siguientes frases del narrador, también homodiegético, constituyen un puente entre CD y TD:

${ }^{6}$ Iouri Lotman, La structure du texle artistique, (Paris: Gallimard, 1973). 
Antes había sido alzarse, liberarse, sublevarse, esconderse, emanciparse, independizarse, pero ahora ya nada de eso era posible, no porque se hubiese logrado o no fuese necesario, sino porque, ya ni siquiera concebir en voz alta, y hasta en voz baja, esas ideas, era recomendable (p. 152).

El discurso literario desoculta en CD y TD la gestación de un proceso que fracasa; más allá de las circunstancias referenciales concretas, atingentes a la revolución cubana, importa el diseño progresivo de un mundo de clausura, opresión y deterioro, como posibilidad ontológica del ser humano y respecto a ese acceso a lo ontológico - a diferencia de lo que ocurriría con lo plasmado por un discurso histórico- pierde todo sentido la intencionalidad de verificación. 
